\title{
On-line mass spectrometry: membrane inlet sampling
}

\author{
Katrin Beckmann · Johannes Messinger • \\ Murray Ronald Badger · Tom Wydrzynski · \\ Warwick Hillier
}

Received: 23 February 2009/Accepted: 9 July 2009/Published online: 4 August 2009

(C) Springer Science+Business Media B.V. 2009

\begin{abstract}
Significant insights into plant photosynthesis and respiration have been achieved using membrane inlet mass spectrometry (MIMS) for the analysis of stable isotope distribution of gases. The MIMS approach is based on using a gas permeable membrane to enable the entry of gas molecules into the mass spectrometer source. This is a simple yet durable approach for the analysis of volatile gases, particularly atmospheric gases. The MIMS technique strongly lends itself to the study of reaction flux where isotopic labeling is employed to differentiate two competing processes; i.e., $\mathrm{O}_{2}$ evolution versus $\mathrm{O}_{2}$ uptake reactions from PSII or terminal oxidase/rubisco reactions. Such investigations have been used for in vitro studies of whole leaves and isolated cells. The MIMS approach is also able to follow rates of isotopic exchange, which is useful for obtaining chemical exchange rates. These types of measurements have been employed for oxygen ligand exchange in PSII and to discern reaction rates of the carbonic anhydrase reactions. Recent developments have also engaged MIMS for online isotopic fractionation and for the study of reactions in inorganic systems that are capable of
\end{abstract}

K. Beckmann · J. Messinger $(\bowtie) \cdot$ M. R. Badger .

T. Wydrzynski · W. Hillier $(\square)$

School of Biology, Australian National University, Canberra,

ACT 0200, Australia

e-mail: Johannes.Messinger@chem.umu.se

W. Hillier

e-mail: Warwick.Hillier@anu.edu.au

K. Beckmann

Max Planck Institut für Bioanorganische Chemie,

45470 Mülheim an der Ruhr, Germany

J. Messinger

Department of Chemistry, Umeå University, 90187 Umeå,

Sweden water splitting or $\mathrm{H}_{2}$ generation. The simplicity of the sampling approach coupled to the high sensitivity of modern instrumentation is a reason for the growing applicability of this technique for a range of problems in plant photosynthesis and respiration. This review offers some insights into the sampling approaches and the experiments that have been conducted with MIMS.

Keywords Membrane-inlet mass spectrometry . Oxygenic photosynthesis - Water-splitting ·

Carbonic anhydrase . Water binding .

Artificial photosynthesis

$\begin{array}{ll}\text { Abbreviations } \\ \text { EI } & \text { Electron impact (or electron ionization) } \\ \text { EIE } & \text { Equilibrium isotope effect } \\ \text { KIE } & \text { Kinetic isotope effect } \\ \text { MIMS } & \text { Membrane inlet mass spectrometry } \\ \text { MS } & \text { Mass spectrometry } \\ \mathrm{m} / z & \text { Mass-to-charge ratio }\end{array}$

Mass spectrometry overview

Mass spectrometry (MS) is an analytical technique that provides selectivity in mass for charged molecules or complexes in gas phase. Based on the initial gas ionization work of Wilhelm Wien in 1898 (Audi 2006), the concept of mass spectrometry using magnetic fields was further developed by Thomson (1913). He observed that a stream of ionized $\mathrm{Ne}^{+}$ions passing through an electromagnetic field would take two different trajectories and concluded that $\mathrm{Ne}$ was composed of atoms of two different atomic 
masses (i.e., ${ }^{20} \mathrm{Ne}$ and ${ }^{22} \mathrm{Ne}$ ). This provided the first evidence for the existence of stable isotopes. Since then, mass spectrometry has advanced to be a versatile and important analytical tool in science and engineering for purposes ranging from analyzing single atoms and small molecules to studying organisms up to the cell level (Kaltashov and Eyles 2005).

The fundamental principle of mass spectrometry is based on the principle of ion optics. Analogous to visible light magnetic lenses shape and contour the beam of charged ions. Mass spectrometery consists of three stages: (i) ion generation; (ii) ion dispersion either temporally or spatially in a magnetic or electric field; and (iii) ion detection. Such components are all maintained under high vacuum for accurate propagation of ion trajectories. The dispersion of different ions is based on perturbation of ion trajectories influenced by a magnetic field. This relationship can be mathematically expressed as follows,

$m / z=B^{2} R^{2} / 2 V$

where a molecule of mass $m$ and charge $z$ will be perturbed by a magnetic field $B$ to bend in a circular path of radius $R$ when acceleration by a potential $V$. These ions trajectories are dispersed based on kinetic energy: the lighter the ion the greater the deflection in the magnetic field. Detection of multiple ions is therefore achievable along the different trajectories with collector arrays, or by sweeping the magnetic field. A practical feature of ion optics is the inability to deflect neutral atoms, thus a prerequisite for mass spectrometry is the ionization of species for detection. The effectiveness of ionization defines the sensitivity of the measurement since in most cases the detection is derived simply from the coulombic charge of an ion entering a detector cup.

\section{Sample ionization}

Ionization of molecules is often the key challenge for mass spectrometry and there are many strategies to enable "molecules to fly" in a mass spectrometer. However, the original and simplest approach is Electron Impact (EI) ionization (Siuzdak et al. 1996), which is readily suited to gases and small organic compounds. This approach utilizes a heated filament to provide a source of emitted electrons that traverse a narrow gap to an electron trap. Intercepting these electrons is a perpendicular stream of gas molecules entering from the vacuum inlet. Within this collision zone, a population of gas molecules undergoes ionization by electron impact and these charged particles are then accelerated in a magnetic field through a slit and leave the source as a beam of ions. The most prominent pathway for the interaction (collisions) of the high-energy electrons with the sample molecules is the creation of positive ions according to:

$\mathrm{M}+\mathrm{e}^{-} \rightarrow \mathrm{M}^{\bullet+}+2 \mathrm{e}^{-}$

In many cases, ionization of the sample can lead to fragmentation of the analyte molecule depending on molecular structure, electron energy, and ion source temperature. The fragmentation patterns (cracking patterns) are highly specific for each molecule and provide structural "finger prints" that enable identification of substances. ${ }^{1}$ In the absence of fragmentation, the singly ionized molecular analyte ions have almost the same mass as the parent molecule (because the ejected electron mass is small in comparison to the total mass of the molecule), thus the mass-to-charge ratio corresponds in such cases directly to the relative molecular mass of the analyte; i.e., $\mathrm{m} / \mathrm{z}=\mathbf{M}$.

Ionization in the modern era includes techniques such as Electro Spray Ionization (ESI) and Matrix Assisted Laser Desorption Ionization (MALDI). These advances provide users with the possibility to study intact proteins with no apparent mass limitation. John Fenn and Koichi Tanaka were honored with the Nobel Prize in Chemistry (2002) for the discovery of ESI-MS. The ESI technique uses a capillary inlet operated with high voltage $(\sim 3-4 \mathrm{kV})$ to create a stream of evaporating charged solvent/analyte droplets that enter the vacuum of the mass spectrometer. The MALDI technique uses typically a pulse laser to a mixture of organic matrix and analyte molecules. The former technique is ideal for liquids, while the latter is suitable for solids such a proteins embedded in films or tissues (Kaltashov and Eyles 2005; Konermann et al. 2008).

\section{Mass analyzer and ion detection}

In order to separate and analyze ions of different mass there are two basic approaches: time or magnetic deflection. To separate ions of different weight by time, the Time-of-Flight (TOF) instrumentation uses the time it takes for ions to fly across an evacuated tube for analysis, while magneticlelectric sector field instruments intercept specific ion trajectories under the influence of an external magnetic/electric field. Both types of instrumentation enable separation of ions according to their individual $\mathrm{m} / \mathrm{z}$ ratio with very high accuracy - the resolution is measured as a few parts per million.

The detector elements for isotope ratio instruments use simple faraday cups to collect the ion currents. The current per $\mathrm{M}^{\bullet+}$ ion is one coulomb and this is converted via high gain amplification into a voltage for readout. Such cups

\footnotetext{
${ }_{1}$ Databases with fragmentation patterns of numerous molecules, including biopolymers are available at e.g. http://webbook.nist.gov/ chemistry/mw-ser.html; MS companies additionally provide library software.
} 
have very long life and can be packed close together in arrays for simultaneous detection of multiple ions. Other detectors used in different mass spectrometers include electron multipliers and micro channel plates, but these are not used in isotope ratio magnetic sector instruments.

\section{Membrane inlets}

Mass spectrometry operates under high vacuum conditions. The vacuum is essential to prevent inter molecular collision of analyte ions with atmospheric gas molecules which would otherwise defocus ion trajectories. An important technical issue of mass spectrometry is how the sample (solid/liquid/gaseous) is introduced into the high vacuum space. An elegant solution to detect processes online in liquid or gaseous samples is to separate the liquid or gaseous phase from the high vacuum space by a gas permeable membrane. This technique named membrane-inlet mass spectrometry (MIMS) was developed by Georg Hoch and Bessel Kok in 1963 (Hoch and Kok 1963) and is schematically shown in Fig. 1. General design features of MIMS cuvettes exemplifying the basic considerations of liquid versus gas phase sampling are displayed in Fig. 2.

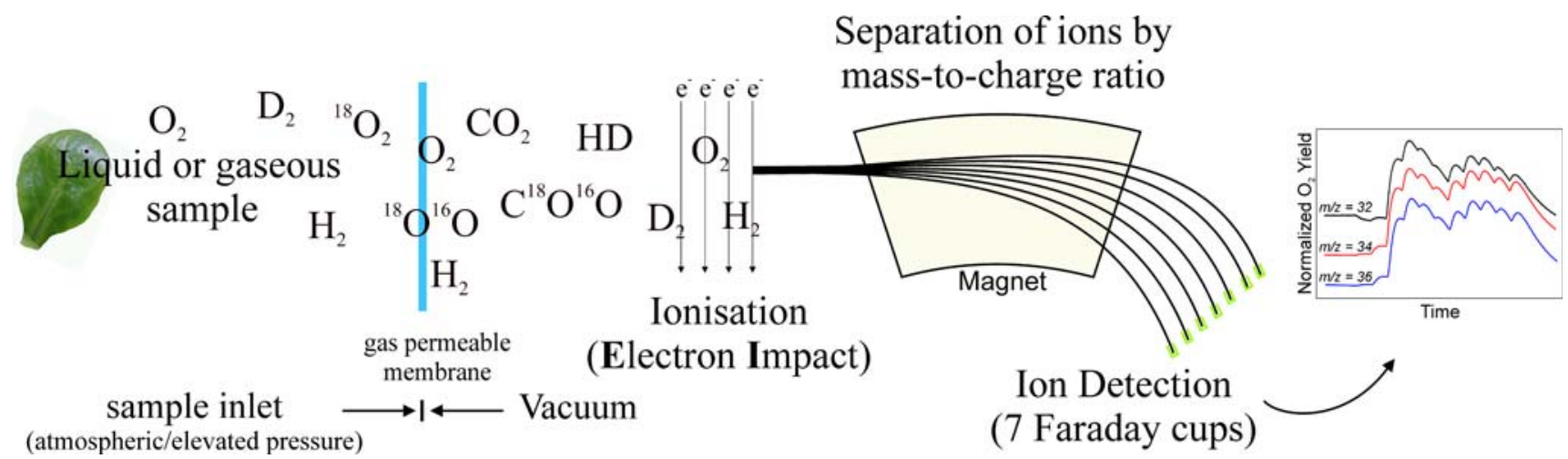

Fig. 1 Pictorial representation of a MIMS set-up demonstrating the gas sampling interface onto a magnetic sector mass spectrometer (i.e., Thermo Finnigan Delta or Isoprime IRMS series). Gases from photosynthesis traverse a membrane into high vacuum and are ionized by electron impact. The ions that are produced are then drawn into a flight tube and are dispersed by a magnetic field into a 7-cup Faraday detector array for detection

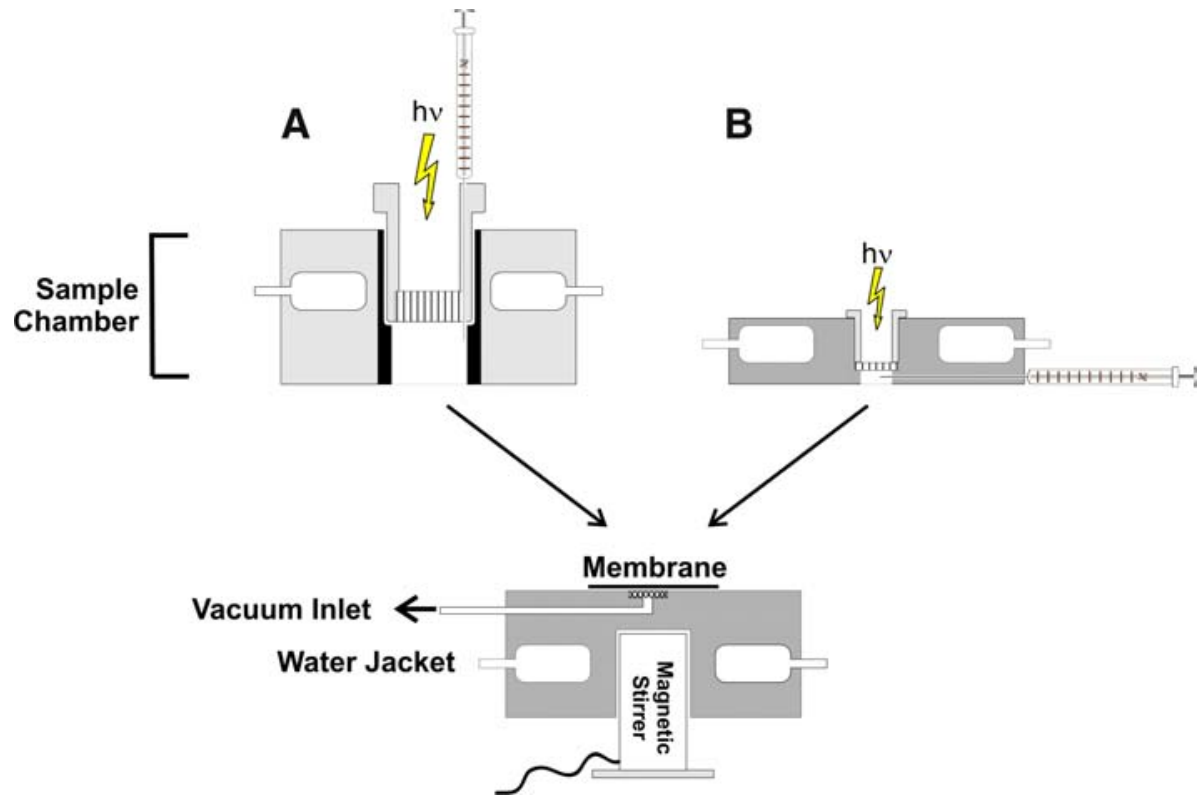

Fig. 2 Membrane-inlet sampling is achieved via different cuvette designs that have a semi-permeable membrane at the high vacuum interface. To avoid boundary layers in liquid phase measurements a magnetic stirrer is placed directly on the membrane. Above the membrane small volume liquid or gas phase cavities are provided so that economical isotopic enrichments can be performed. For photosynthetic studies of leaves (a) sealed cuvettes with volumes $\sim 1 \mathrm{ml}$ are used with a window for illumination, whereas solutions measurements (b) can employ sample chambers with considerably smaller volumes. The cuvette design incorporates injection ports and thermal regulation via water cooling 
The key component of MIMS is a membrane that is typically $10-100 \mu \mathrm{m}$ thick and can be a few $\mathrm{cm}^{2}$ in size. To prevent collapse it requires support from a porous supporting material that does not impose a significant diffusion barrier. Porous plastic sheeting or thin metal supports with fine holes can provide this function. To prevent water vapor entering the mass spectrometer, particularly as result of a membrane puncture, a cryogenic trap is installed between membrane and ion source. In addition to trapping water vapor the trap can be used to differentially remove other organics or gasses by choosing the trap temperature. The trap may be filled for example with dry ice/ethanol $(\sim 200 \mathrm{~K})$ or liquid nitrogen $(77 \mathrm{~K})$.

\section{Membrane properties}

As mentioned above, in MIMS a semi-permeable membrane functions as analyte inlet system into the high vacuum of the mass spectrometer. The membrane is permeable, not porous: the analyte molecules do not diffuse through the membrane, but follow a three step process, termed pervaporation (Silva et al. 1999; Johnson et al. 2000; Konermann et al. 2008). In the first step, the gas is adsorbed onto the surface of the membrane; in the second step the analyte molecules enter the membrane (permeation); and the third step is desorption of the molecules into the vacuum on the other side of the membrane. The gas transmission rate $\left(k_{\text {trans }}\right)$ across the membrane is given by Fick's law of diffusion (Hoch and Kok 1963)

$k_{\text {trans }}=(P A \Delta p) / l$

and is defined by the gas permeability $(P)$ constant, ${ }^{2}$ the area of the membrane inlet $(A)$, the partial pressure difference across the membrane $(\Delta p)$, and the membrane thickness $(l)$. As the partial pressure of gases on the low pressure (vacuum) side of the membrane is very small, the transmission rate is proportional to the gas concentration in the liquid phase. The overall sensitivity (gain factor) of detection is greater for thinner membranes and membrane types with high permeability. There are also effects due to relative diffusion of different molecular weight gases and "stickiness" of gas such as $\mathrm{CO}_{2}$. Therefore, for quantitative measurements, calibrations need to be performed for each different analyte using a volume of a liquid or calibration gas.

The choice of membrane depends on the experiment. If high sensitivity is required then a highly permeable membrane and a large inlet area are advantageous to facilitate a higher rate of gas sampling. It may also be possible in some circumstances to operate with a higher vacuum to influence

\footnotetext{
2 The permeability is a product of the diffusion constant (D) and solubility coefficient of the gas in the membrane.
}

greater gas transmission. In contrast, if long term sampling is required with near constant background gas concentrations, then a low consumption (i.e., thicker) membrane is required and/or use of a small sampling area. Most membranes have a good chemical resistance and if measurements are undertaken at elevated pressure (e.g., 20 bar) a supported membrane with an embedded metal grid can be used. A range of membranes suitable for MIMS applications are the following: silicone membranes (MEM-213, Mem Pro); Teflon films such as FET or AF (DuPont); silicone rubber; oxygen electrode membranes ${ }^{3}$; HDPE plastic films (various sources); silicon membranes with embedded metal grid (Franatech GmbH, Germany). Thus, the choice of MIMS sensitivity versus gas concentration stability is an important factor in the experimental design.

\section{Isotopic enrichment}

Isotopes are defined as atoms with the same number of protons, but a different number of neutrons and thus differ in atomic weight. There are 80 elements with stable isotopes (26 with only one isotope) and 94 elements that occur naturally on earth. The MIMS approach makes use of the stable isotopes which can be found at natural abundance or purchased from many suppliers in varying enrichments. Table 1 lists many elements that are useful to study with photosynthesis and respiration in plants. The numerical distribution of stable isotopes has in many cases a very high level of certainty (Coplen et al. 2002).

The level of isotopic enrichment $(\varepsilon)$ is a measure of the abundance between 0 and $100 \%$. The lower limit in practice is given by Earth's natural abundance of isotopes and these ratios provide an incisive tool for examining cycling of elements in biochemical or geochemical reactions. For mono-atomic species, or molecules where only one atom varies in weight, the enrichment level is simply the ratio between the abundance of the various isotopic species. For diatomic molecules, which effectively represent most of the atmospheric gases, the level is given by the binomial expansion. For oxygen ${ }^{4}$ this is:

$(m / z) 32: 34: 36=(1-\varepsilon)^{2}: 2 \varepsilon(1-\varepsilon): \varepsilon^{2}$

and the total $32+34+36$ given as $100 \%$. The relationship between the relative concentration (abundance) and

\footnotetext{
3 YSI provides a $12.5 \mu \mathrm{m}$ high sensitivity and a $25.5 \mu \mathrm{m}$ standard sensitivity Teflon membrane, Hansatech a $25 \mu \mathrm{m}$ Teflon membrane.

${ }^{4}$ Molecular oxygen is somewhat simplified as there is also a $0.0374 \%$ enrichment of ${ }^{17} \mathrm{O}$ at natural abundance. This can be taken into consideration by expansion of the Eq. 4. However, molecular oxygen species from ${ }^{17} \mathrm{O}$ at $\mathrm{m} / \mathrm{z}=33,34$ and 35 at natural abundance are very small $(0.07462,0.00001$, and $0.00015 \%$ respectively) and for MIMS approaches can practically be ignored.
} 
Table 1 Stable isotopes that are important for isotope ratio MS and their levels of natural abundance

\begin{tabular}{llcc}
\hline Element & Symbol & Mass of atom $(\mathrm{u})$ & Abundance $(\%)$ \\
\hline Hydrogen & ${ }^{1} \mathrm{H}$ & 1.007825 & 99.9885 \\
Deuterium & ${ }^{2} \mathrm{H}$ & 2.014102 & 0.115 \\
Carbon & ${ }^{12} \mathrm{C}$ & 12.000000 & 98.93 \\
& ${ }^{13} \mathrm{C}$ & 13.003355 & 1.07 \\
Nitrogen & ${ }^{14} \mathrm{~N}$ & 14.003074 & 99.632 \\
& ${ }^{15} \mathrm{~N}$ & 15.000109 & 0.368 \\
Oxygen & ${ }^{16} \mathrm{O}$ & 15.994915 & 99.757 \\
& ${ }^{17} \mathrm{O}$ & 16.999132 & 0.038 \\
& ${ }^{18} \mathrm{O}$ & 17.999160 & 0.205 \\
Argon & ${ }^{36} \mathrm{Ar}$ & 35.967546 & 0.3365 \\
& ${ }^{38} \mathrm{Ar}$ & 37.962732 & 0.0632 \\
& ${ }^{40} \mathrm{Ar}$ & 39.962383 & 99.6003 \\
\hline
\end{tabular}

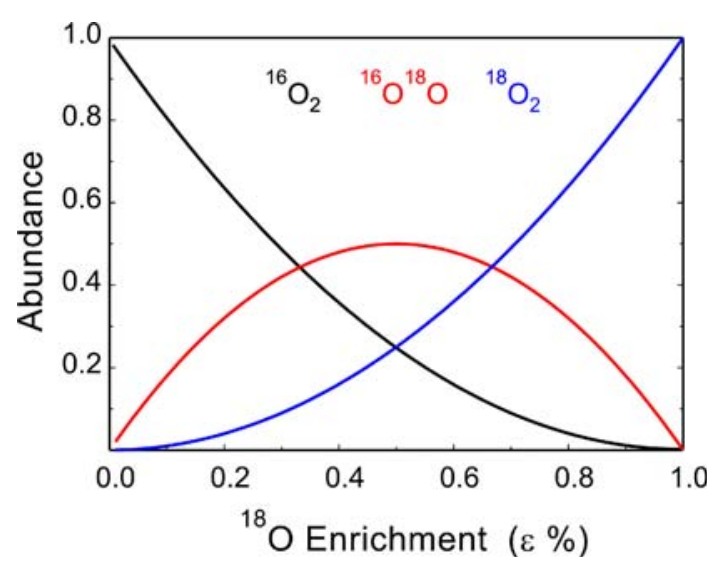

Fig. 3 Isotopic enrichment for di-atomic molecules follows a binomial distribution. The figure depicts the changing relative concentrations for molecular oxygen species with changing ${ }^{18} \mathrm{O}$ enrichment $(\varepsilon)$

the enrichment is shown in Fig. 3. A practical aspect of this relationship is that at low enrichment levels the concentrations of doubly labeled species are significantly lower than their enrichment $\varepsilon$, for example, the natural abundance of ${ }^{18} \mathrm{O}$ is $0.2039 \%$, but the abundance of the $\mathrm{m} / \mathrm{z}=36$ species is only $0.00042 \%$.

Another term that is often introduced for changing levels of enrichment is the mole fraction. An example of this is shown below for ${ }^{13} \mathrm{CO}_{2}$, where the ${ }^{18} \mathrm{O}$ mole fraction, which is typically expressed as ${ }^{18} \alpha$, gives an instantaneous measure of enrichment.

$$
{ }^{18} \alpha=\frac{[47]+2[49]}{2([45]+[47]+[49])}
$$

Where for example [45] corresponds to the relative concentration of ${ }^{13} \mathrm{C}^{16} \mathrm{O}^{16} \mathrm{O}$. Thus, the concentrations of ${ }^{13} \mathrm{C}$ species at $\mathrm{m} / \mathrm{z}=45,47$ and 49 are used to derive the mole fraction. This enrichment expression is particularly useful for tracking the overall speed of the reaction relative to the background (Mills and Urey 1940; Silverman 1982).

\section{Practical applications of MIMS}

Whole leaf photosynthesis and respiration

Photosynthesis and respiration are important biological processes which involve the flux of $\mathrm{O}_{2}$ and $\mathrm{CO}_{2}$ species into and out of biological tissues, particularly leaves. The benefits of studying whole leaf photosynthesis and respiration by net $\mathrm{CO}_{2}$ and $\mathrm{O}_{2}$ concentrations have been a strong incentive for using field instrumentation such as the infrared gas analyzers like the LI-6400 (LI-COR Environmental, Nebraska USA). However, when it comes to the separation of in vivo $\mathrm{CO}_{2}$ and $\mathrm{O}_{2}$ fluxes mass spectrometry is the technique of choice because of its ability to monitor $\mathrm{CO}_{2}$ and $\mathrm{O}_{2}$ species with one instrument and to selectively analyze all isotopes of these gases. The unique fact that makes isotopic approaches particularly useful in photosynthetic organisms is that the $\mathrm{O}_{2}$ evolved from PSII has the isotopic signature of water while the oxygen uptake reactions consumes the gaseous oxygen. Thus, measurement of gross oxygen evolution and gross oxygen uptake can be achieved by the use of enriched ${ }^{18} \mathrm{O}_{2}$ atmospheres and $\mathrm{H}_{2}^{16} \mathrm{O}$ (Radmer and Kok 1976). Although there are obvious issues with field deployment, mass spectrometry has been crucial in resolving $\mathrm{O}_{2}$ and $\mathrm{CO}_{2}$ fluxes in plants and algae that can be brought into the laboratory. The first experiments with algae (Radmer and Kok 1976; Radmer and Ollinger 1980b) and leaves (Canvin et al. 1980) answered many important questions regarding $\mathrm{CO}_{2}$ and $\mathrm{O}_{2}$ metabolism in plants.

In practice, the measurements are performed on-line with MIMS. The sample cuvette is equipped with a low consumption membrane and operates for example with a $1 \mathrm{ml}$ sample volume to accommodate the leaf disc and gas additions, see Fig. 2. The sample chamber must also have a gas $\left(\mathrm{O}_{2}\right)$ tight seal to the outside, as gas leakage invalidates the approach. The plant tissue then can be illuminated to determine rates of photosynthesis: $\mathrm{O}_{2}$ evolution $\left(\uparrow \mathrm{O}_{2}\right)$, rates of $\mathrm{O}_{2}$ uptake $\left(\downarrow \mathrm{O}_{2}\right)$, and net rates of $\mathrm{CO}_{2}$ assimilation. In order to facilitate differentiation between competing $\mathrm{O}_{2}$ fluxes isotopic labeling is undertaken by initially flushing the cuvette with $\mathrm{N}_{2}$ before addition of ${ }^{12} \mathrm{CO}_{2}$ and ${ }^{18} \mathrm{O}_{2}$ as substrates for Rubisco and terminal oxidase proteins. Thus, the ${ }^{18} \mathrm{O}_{2}$ respiration/uptake fluxes are distinguished from ${ }^{16} \mathrm{O}_{2}$ evolution from Photosystem II (PSII). The corrections for net rate of $\mathrm{O}_{2}$ uptake and net $\mathrm{O}_{2}$ evolution (Radmer et al. 1978; Canvin et al. 1980; Maxwell et al. 1998; Ruuska et al. 2000) are based upon relative oxygen enrichments, i.e., $\left[{ }^{16} \mathrm{O}\right] /\left[{ }^{18} \mathrm{O}\right]$ and the rate of change in the $\mathrm{m} / z=36\left(\Delta^{18} \mathrm{O}_{2}\right)$ or $\mathrm{m} / \mathrm{z}=32\left(\Delta^{16} \mathrm{O}_{2}\right)$ signals; i.e. 

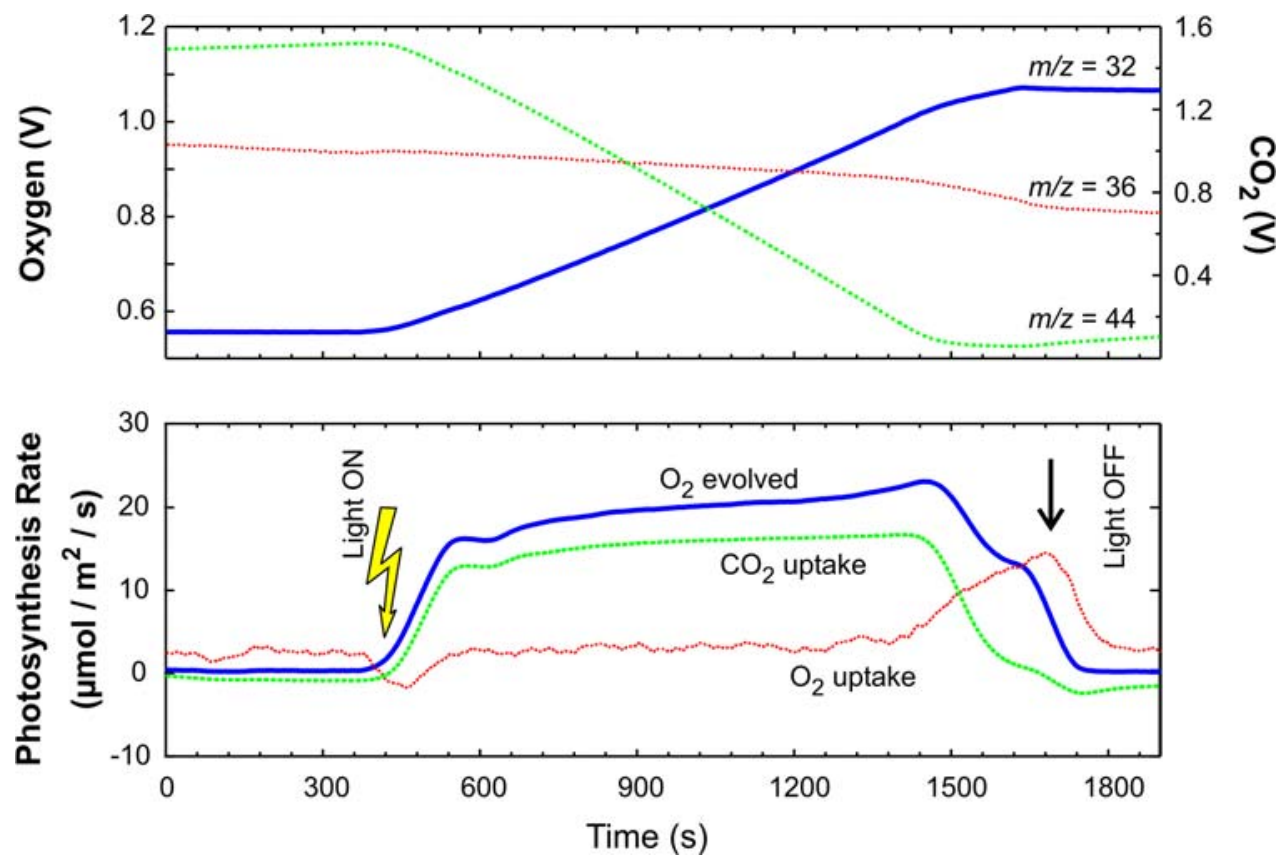

Fig. 4 Gas exchange measurements of intact leaves can be studied in MIMS cuvettes. The sealed chamber contains a leaf disk and is purged with $\mathrm{N}_{2}$ before addition of $2 \%{ }^{12} \mathrm{CO}_{2}$ and $20 \%{ }^{18} \mathrm{O}_{2}$. The upper figure shows the raw signals (in Volt) at $\mathrm{m} / z=32$ for photosynthetic water splitting, $\mathrm{m} / z=36$ for oxygen uptake pathways that include oxygenation reaction from Rubisco and terminal oxidase reaction in respiration. The $\mathrm{m} / z=44$ shows rates of $\mathrm{CO}_{2}$ uptake. The lower part of this figure depicts absolute rates of respiration and

$$
\begin{aligned}
& \downarrow \mathrm{O}_{2}=\Delta \Delta^{18} \mathrm{O}_{2} \times\left(1+\frac{\left[{ }^{16} \mathrm{O}_{2}\right]}{\left[{ }^{18} \mathrm{O}_{2}\right]}\right) \\
& \uparrow \mathrm{O}_{2}=\Delta \Delta^{16} \mathrm{O}_{2}-\Delta \Delta^{18} \mathrm{O}_{2}\left(\frac{\left[{ }^{16} \mathrm{O}_{2}\right]}{\left[{ }^{18} \mathrm{O}_{2}\right]}\right)
\end{aligned}
$$

The data from a leaf experiment are shown in Fig. 4. The MIMS cuvettes are custom made and injections can be made via small sealable holes in the cap (Fig. 2a). The centre of the plug can be made to accommodate fiber optics for illumination and simultaneous fluorescence measurements concomitant with the recordings of $\mathrm{O}_{2}$ and $\mathrm{CO}_{2}$ signals (Canvin et al. 1980; Maxwell et al. 1998; Ruuska et al. 2000).

Liquid-phase measurements of photosynthesis in solution (i.e., algae, chloroplasts) are equivalent in concept to leaf gas exchange (Badger and Andrews 1982; Espie et al. 1988; Hanson et al. 2003), except that there are different solubilities of the gases which alter measurement sensitivities. Thus, $\mathrm{O}_{2}$ is measured with greater sensitivity while $\mathrm{CO}_{2}$ may be less sensitive due to the fact that $\mathrm{CO}_{2}$ equilibrates with hydrogencarbonate (formerly termed bicarbonate) in solution and $\mathrm{CO}_{2}$ may be only a small fraction of the total inorganic carbon used for photosynthesis. The ratio of $\mathrm{CO}_{2}$ /hydrogen carbonate will depend on the $\mathrm{pH}$ of photosynthesis. The initial dark period determines net rates of ${ }^{18} \mathrm{O}_{2}$ uptake and $\mathrm{CO}_{2}$ generation from respiration. At the arrow illumination commences and there is net generation of ${ }^{16} \mathrm{O}_{2}$, a net $\mathrm{CO}_{2}$ uptake and slightly increased ${ }^{18} \mathrm{O}_{2}$ uptake. After a few minutes the total $\left[\mathrm{CO}_{2}\right]$ in the chamber begins to fall and Rubisco oxygenase reactions increase, as seen by the dramatic increase in ${ }^{18} \mathrm{O}_{2}$ uptake. For more details see (Canvin et al. 1980; Maxwell et al. 1998)

the assay reaction and will decrease at alkaline $\mathrm{pH}$. Liquidphase measurements are particularly useful for studying aquatic photosynthesis, since for such systems there are no other techniques which allow for detailed examinations of both $\mathrm{CO}_{2}$ and $\mathrm{O}_{2}$ fluxes associated with photosynthesis (Badger et al. 1994; Palmqvist et al. 1994; Woodger et al. 2005; Rost et al. 2006).

\section{Carbonic anhydrase}

The carbonic anhydrase (CA) enzymes (EC 4.2.1.1) are vital for plant and animal metabolism as they equilibrate $\mathrm{CO}_{2}$ concentrations in solution with hydrogencarbonate. The catalyzed CA reaction is extremely rapid and involves a number of enzymatic intermediates and rapid proton equilibration steps (Gibbons and Edsall 1963; Lindskog and Coleman 1973; Silverman and Lindskog 1988). However, the overall reaction can be described in simplified form as a single rate determining hydration/dehydration reaction; i.e.

$\mathrm{CO}_{2}+\mathrm{H}_{2} \mathrm{O} \underset{k_{2}}{\stackrel{k_{1}}{\longleftrightarrow}} \mathrm{HCO}_{3}^{-}+\mathrm{H}^{+}$

Using a MIMS approach, the forward hydration rate $k_{1}$ and reverse dehydration rate $k_{2}$ can be determined (Hillier et al. 
2006; McConnell et al. 2007), or an expression of reaction rate based on the change in enrichment, i.e., ${ }^{18} \alpha$ from Eq. 6, can be derived (Mills and Urey 1940; Silverman 1982).

The assay of CA activity by MIMS has several advantages compared to other techniques: it is rapid and accurate over a wide temperature ranges, but a unique feature is that enzymatic activity is obtained at chemical equilibriumi.e., under conditions of equilibrated $\mathrm{CO}_{2}$ and $\mathrm{HCO}_{3}{ }^{-}$ concentration. Other CA assays in contrast, using ${ }^{14} \mathrm{C}$ labeling or $\mathrm{pH}$ transients, are reliant on rapid changes in the equilibrium that are slowed on ice and are not obtained at chemical equilibrium.

The principle of the CA-MIMS assay is based upon isotopic exchange of ${ }^{18} \mathrm{O}$-label between $\mathrm{HCO}_{3}{ }^{-}$on one side of Eq. 9 and $\mathrm{CO}_{2}$ and water on the other side of the reaction. The MIMS assay monitors the $\left[\mathrm{CO}_{2}\right]$ in solution, and thus provides a continuous real-time determination of one half of the reaction (Gerster 1971; Tu and Silverman 1975; Silverman 1982). As the isotopic approach deals with slow isotopic exchange reactions, it may be followed accurately for tens of minutes timescale. In practice, the MIMS assay is primed by the initial addition of a known amount of ${ }^{18} \mathrm{O}$-hydrogencarbonate from a $200-500 \mathrm{mM}$ stock. ${ }^{5}$ The assay is best performed with ${ }^{13} \mathrm{C}$-labeled Na-hydrogencarbonate as backgrounds are small, but can also be performed with ${ }^{12} \mathrm{C}$ material if needed. The peaks of ${ }^{13} \mathrm{CO}_{2}$ are then followed at $\mathrm{m} / \mathrm{z}=49,47$ and 45 for the ${ }^{13} \mathrm{C}^{18,18} \mathrm{O}_{2},{ }^{13} \mathrm{C}^{16,18} \mathrm{O}_{2}$, and ${ }^{13} \mathrm{C}^{16,16} \mathrm{O}_{2}$, respectively (Silverman 1982; Badger and Price 1989), as shown in Fig. 5a. After injection of hydrogencarbonate a rapid initial increase at $m / z=49$, representing the initial short chemical equilibration between aqueous $\mathrm{H}^{13} \mathrm{C}^{18} \mathrm{O}_{3}{ }^{-}$and gaseous ${ }^{13} \mathrm{C}^{18} \mathrm{O}_{2}$ is observed (please notice the log scale on the time axis). This is followed by phases of isotopic equilibration with the eventual formation of ${ }^{13} \mathrm{C}^{16} \mathrm{O}_{2}$ as the $\mathrm{m} / \mathrm{z}=45$ species. Water provides the final sink for the ${ }^{18} \mathrm{O}$ re-distribution and undergoes with time a gradual enrichment above natural abundance (Hillier et al. 2006; McConnell et al. 2007).

It is also possible to express isotopic exchange more qualitatively as the change in ${ }^{18} \mathrm{O}$ enrichment $\left({ }^{18} \alpha\right)$ as given by Eq. 6 . When the enrichment is plotted as the natural $\log \left({ }^{18} \alpha\right)$ for $\mathrm{CO}_{2}$ versus time (Mills and Urey 1940) the slope of the line gives a measure of the pseudo first-order rate constant for hydration of $\mathrm{CO}_{2}$ by the $\mathrm{CA}$ reaction, see Fig. 5b. The rate of this reaction is commonly compared to the uncatalysed rate in the same assay solution (Badger and

\footnotetext{
$\overline{{ }^{5} \mathrm{HC}^{18} \mathrm{O}_{3}{ }^{-}}$is prepared by incubating $\mathrm{NaHCO}_{3}$ in $>95 \%{ }^{18} \mathrm{O}$-water. Isotopic equilibration is $\sim 24 \mathrm{~h}$ at room temperature and converts the hydrogencarbonate to triply ${ }^{18} \mathrm{O}$ labeled species.
}

Price 1989; Von Caemmerer et al. 2004; Clausen et al. 2005).

Related approaches can be taken to probe for example for binding sites of carbonate or hydrogencarbonate in PSII (Shevela et al. 2008). In these experiments, it is attempted to replace the bound inorganic carbon $\left(\mathrm{C}_{\mathrm{i}}\right)$ by the addition of a molecule (formate) that competes for the binding site, or by the destruction of the binding site via the addition of a strong reductant. In both cases the released $\mathrm{C}_{\mathrm{i}}$ is converted by the intrinsic or externally added $\mathrm{CA}$ into $\mathrm{CO}_{2}$ and can then be detected via the MIMS approach. Figure 6 demonstrates that injection of formate releases carbonate/hydrogencarbonate from the non-heme iron at the acceptor side of PSII (see also Govindjee et al. 1991, 1997), while the destruction of the $\mathrm{Mn}_{4} \mathrm{O}_{x} \mathrm{Ca}$ cluster does not lead to a release of $\mathrm{C}_{\mathrm{i}}$. This demonstrates the absence of a tightly bound $\mathrm{C}_{\mathrm{i}}$ within the water oxidizing complex (see also Ulas et al. 2008; Aoyama et al. 2008).

\section{Real time isotopic fractionation}

Isotopic fractionation is the ratio of one isotopic species (isotopologue) over another and brings with it information about chemical reactions. The fractionation can be due to (1) chemical diffusion such as $\mathrm{CO}_{2}$ assimilation in leaves (Farquhar et al. 1989), or to chemical reactions where (2) there is a kinetic isotope effect (KIE, i.e., an isotope dependant difference in reaction rate) or (3) an equilibrium isotope effect (EIE, i.e., a change in the equilibrium concentration of an isotopic species). Traditionally measurements are typically performed with a time-dependent sampling of the concentrations of the products (e.g., Guy et al. 1993; Tian and Klinman 1993; Ribas-Carbo et al. 2005). This technique usually requires chromatographic separation or molecular sieve/freeze trapping of gases prior to analysis, and in the case of molecular oxygen, its initial conversion into $\mathrm{CO}_{2}$. Alternatively, such experiments can also be undertaken as real-time continuous measurement of gas concentrations using a MIMS approach. In this case, both reaction rates (i.e., given as $\Delta \mathrm{O}_{2}$ ) and the absolute concentration of substrate (i.e., $\left[\mathrm{O}_{2}\right]$ ) are measured simultaneously for unlabeled and labeled isotopes. The true isotopic discrimination, $f$, of a reaction can be derived by measuring the ratio of the reaction rates, over the ratio of substrate concentrations, e.g.,

$f=\left(\frac{\Delta^{34} \mathrm{O}_{2} /\left[{ }^{34} \mathrm{O}_{2}\right]}{\Delta^{32} \mathrm{O}_{2} /\left[{ }^{32} \mathrm{O}_{2}\right]}\right) \times 1000$

The key advantage of this technique is that discrimination values can be derived in a matter of minutes (the time for a reaction) rather than days (the time for subsequent gas 

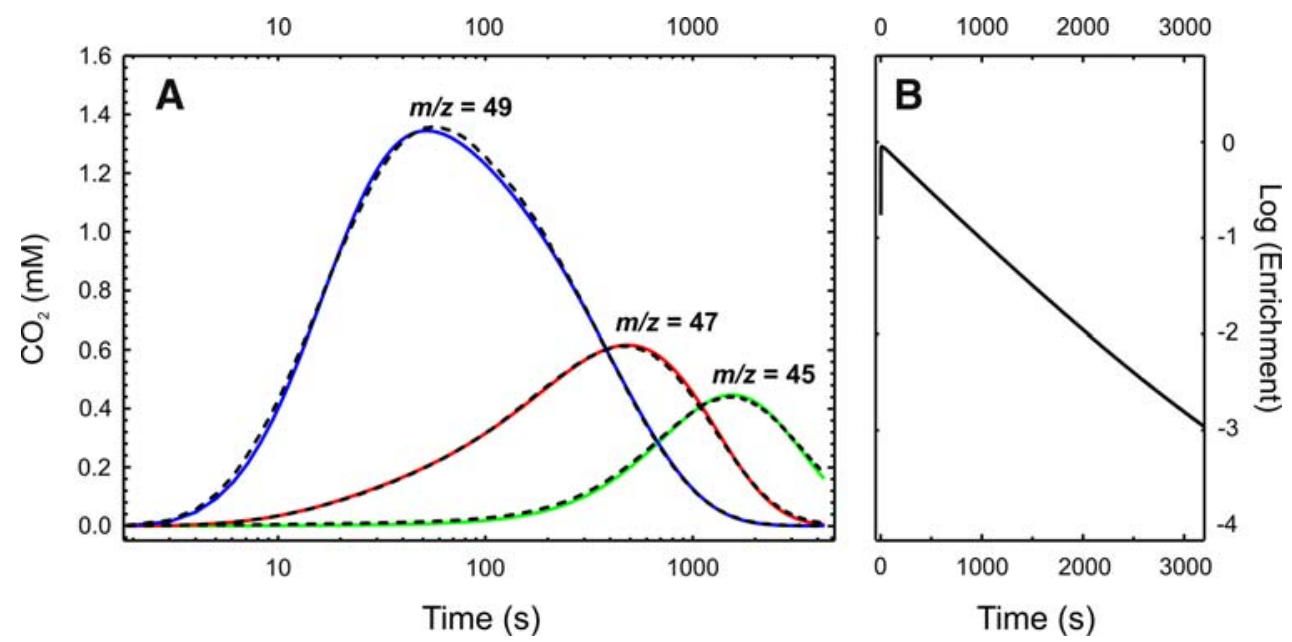

Fig. 5 This assay for carbonic anhydrase activity of photosystem II samples shows the distribution of ${ }^{13} \mathrm{CO}_{2}$ species following the injection of $50 \mathrm{mM} \mathrm{H}{ }^{13} \mathrm{C}^{18} \mathrm{O}_{3}{ }^{-}$into the liquid sample in the MIMScuvette. The experimental data (solid lines) were used to derive fitted

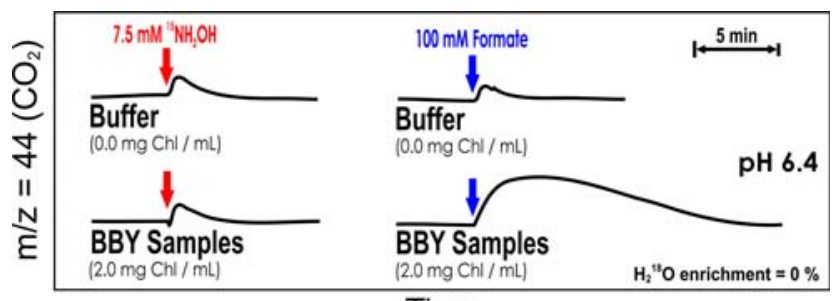

Time

Fig. 6 Probing the binding of inorganic carbon $\left(\mathrm{C}_{\mathrm{i}}\right)$ to photosystem II. The right side shows that the addition of formate to PSII induces a release of $\mathrm{C}_{\mathrm{i}}$ into the medium which is clearly above the background measured by injection of formate into buffer. The released $\mathrm{C}_{\mathrm{i}}$ is converted to $\mathrm{CO}_{2}$ by the intrinsic carbonic anhydrase (CA) activity of thylakoids and by added $\mathrm{CA}$. The released $\mathrm{CO}_{2}$ corresponds to about $0.3 \mathrm{C}_{\mathrm{i}} /$ PSII. Left side: addition of hydroxylamine at concentrations known to rapidly reduce the $\mathrm{Mn}_{4} \mathrm{O}_{\mathrm{x}} \mathrm{Ca}$ cluster and to release the manganese as $\mathrm{Mn}$ (II) into the medium did not lead to $\mathrm{CO}_{2}$ signals above background (left side). ${ }^{15} \mathrm{~N}$-labeled hydroxylamine was used to shift the signal of $\mathrm{N}_{2} \mathrm{O}$, which is produced during the reduction, to mass 46

extraction and processing). This technique is in its infancy, but has been used already to study $\mathrm{CO}_{2}$ discrimination in Rubisco carboxylase reactions and $\mathrm{O}_{2}$ discrimination in mitochondrial terminal oxidases (McNevin et al. 2006; McNevin et al. 2007; Armstrong et al. 2008).

\section{Substrate water exchange in PSII}

Isotopic exchange of water-derived oxygen ligands of the oxygen-evolving complex (OEC) into $\mathrm{O}_{2}$ has been of long standing interest with PSII, because it contains information of how, when, and where substrate-water is bound to the OEC and in what manner it is oxidized to amplitudes (dashes) at $\mathrm{m} / \mathrm{z}=49$ (blue) $\mathrm{m} / \mathrm{z}=47$ (red); $\mathrm{m} / \mathrm{z}=45$ (green) and are plotted on a log time scales. A second plot to the right (B) gives the $\log$ of the ${ }^{18} \mathrm{O}$ enrichment (also termed ${ }^{18} \alpha$ ) according to Eq. 5. For more details see (Hillier et al. 2006; McConnell et al. 2007)

molecular $\mathrm{O}_{2}$ - e.g. via: (1) a sequence of oxidation steps involving partial water oxidation intermediates; or (2) a concerted reaction mechanism during the $\mathrm{S}_{3} \rightarrow \mathrm{S}_{0}$ transition. A MIMS approach to this question was first employed by Radmer and Ollinger (Radmer and Ollinger 1980a). They attempted to determine the rate of appearance of ${ }^{18} \mathrm{O}$ in the $\mathrm{O}_{2}$ products of water splitting by PSII samples suspended in ${ }^{18} \mathrm{O}$-enriched water. The experiment is analogous to stop-flow experiments and requires rapid injection/ mixing of isotopically labeled water into the suspension of photosynthetic samples followed by a series of light flashes to photogenerate $\mathrm{O}_{2}$. This first MIMS experiment indicates that water exchanges rapidly and by inference conceded that there are no non-exchangeable stable water oxidation products (e.g., bound peroxides) up to the $S_{3}$ state of the OEC. This work and others that followed (Radmer and Ollinger 1980a, 1986; Bader et al. 1993) were limited by mixing/stabilization times of $>30 \mathrm{~s}$, and it wasn't until more rapid mixing techniques were developed that also strongly reduced the $\mathrm{O}_{2}$ background rise from the injection of the labeled water that more specific information about water binding could be learned (Messinger et al. 1995).

With the ability to resolve exchange rates of the two substrate water molecules in intermediate steps of the water oxidation reaction (S-states) it was then possible to study water binding interactions with the surrounding proteins, metals, and amino acids to learn about the nature of the two substrate water binding sites (Hillier et al. 1998; Hillier and Wydrzynski 2000; Hendry and Wydrzynski 2003; Singh et al. 2008). The experimental behavior of the $\mathrm{O}_{2}$ flash yields for the $S_{3}$-state are given in Fig. 7 and shows biphasic behavior for $\mathrm{m} / \mathrm{z}=34$ and monophaisc behavior for $m / z=36$. The biphasic behavior is characteristic for 

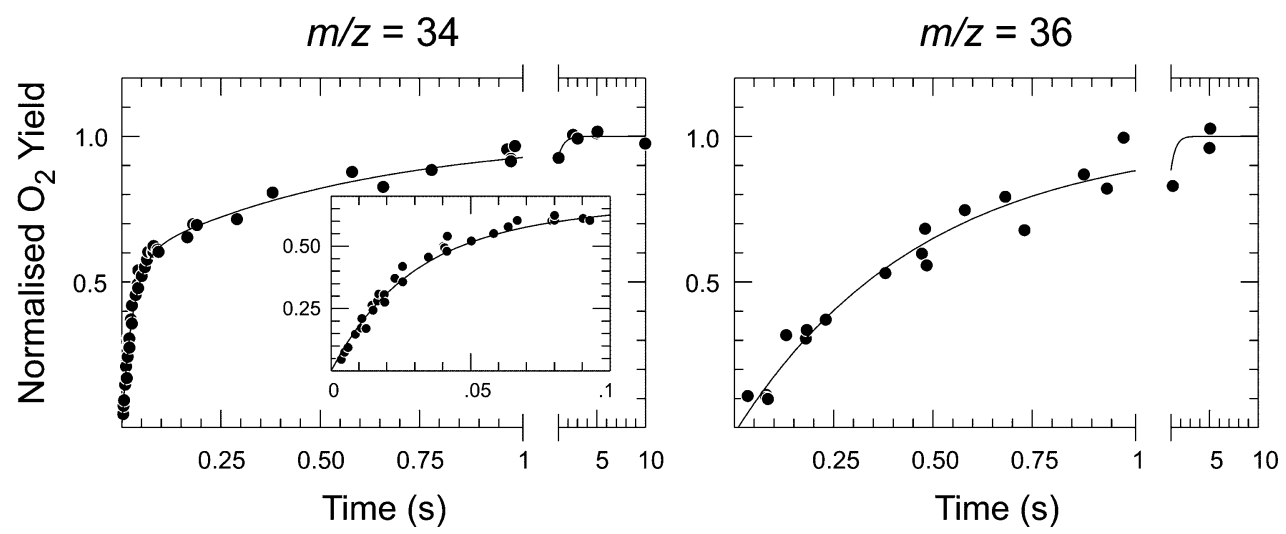

Fig. 7 A rapid mixing liquid phase cuvette is used to study ${ }^{18} \mathrm{O}$ exchange kinetics with PSII. The oxygen yield is followed as a function of the incubation time of rapidly injected $\mathrm{H}_{2}^{18} \mathrm{O}$ with spinach thylakoids in the " $\mathrm{S}_{3}$ state". Measurements were made at $\mathrm{m} / z=34$

the exchange of the two non-equivalent substrate sites. The monophasic $m / z=36$ data is indicative of the rate determining step and is kinetically equivalent to the slow phase of exchange at $\mathrm{m} / \mathrm{z}=34$ (Messinger et al. 1995, Hillier et al. 1998).

In order to evaluate the S-state dependence of the ${ }^{18} \mathrm{O}$ exchange rates, the sample is preset in the various $\mathrm{S}$ states with appropriate pre-flash protocols. The sample chamber is optically coupled to a bank of three xenon flash lamps via a 3-to-1 fiber optic to enable fast turnover sequences to be initiated. The ${ }^{18} \mathrm{O}$-water injection can be accomplished with $\mathrm{at}_{1 / 2} \sim 5 \mathrm{~ms}$ and subsequent $\mathrm{Xe}$ turnover flashes given 5-10 ms apart to photogenerate $\mathrm{O}_{2}$. Since the actual instrumental response time is relatively slow $(\sim 10 \mathrm{~s}$ due to the diffusion of the $\mathrm{O}_{2}$ gas across the semi-permeable membrane into the inlet line), the flash spacing of a subsequent flash sequence that is used to normalize the oxygen signals is increased, typically to $20 \mathrm{~s}$. As such, in order to retard the deactivation reactions of the higher S states, the temperature of the sample is reduced (usually to $10^{\circ} \mathrm{C}$ ). Details of the set-up have been published earlier (Messinger et al. 1995; Hillier and Wydrzynski 2000, 2004).

The kinetics of exchange in Fig. 7 and elsewhere appears first order for $\mathrm{m} / \mathrm{z}=36$ and is fit to pseudo firstorder exchange behavior:

${ }^{36} \mathrm{Y}=\left[1-\exp \left(-{ }^{36} k \mathrm{t}\right)\right]$

In contrast, the $m / z=34$ data reveal two distinct kinetic phases that are fit to two pseudo first-order components, i.e.

${ }^{34} \mathrm{Y}=0.57\left[1-\exp \left(-{ }^{34} k_{2} \mathrm{t}\right)\right]+0.43\left[1-\exp \left(-{ }^{34} k_{1} \mathrm{t}\right)\right]$

As the apparent kinetics at $m / z=34$ of the two phases differ by at least a factor of 10 , the fast phase of exchange is virtually complete before the slow phase begins. This behavior is a reason for the non-equivalent amplitudes of

(left) and $m / z=36$ (right) and the $\mathrm{O}_{2}$ yields were recorded as dots that are fitted to first-order kinetics. For more details see Messinger et al. 1995; Hillier and Wydrzynski 2004

the two $\mathrm{m} / \mathrm{z}=34$ components. The amplitudes of the two phases are also influenced by the enrichment (Messinger et al. 1995; Hillier and Wydrzynski 2004).

\section{Photobiological hydrogen production}

tThere are three types of photobiological $\mathrm{H}_{2}$ producing processes in nature: (i) oxygenic photosynthesis coupled to hydrogenases, (ii) oxygenic photosynthesis coupled to nitrogenases, and (iii) non-oxygenic photosynthesis coupled to nitrogenases (for review see Ghirardi et al. 2009). Understanding these biological processes on the level of whole cell metabolism and elucidating the reaction mechanisms of the involved enzymes is expected to allow optimizing the yields of the biological processes and constructing efficient artificial systems (Melis and Happe 2004; Lubitz et al., 2008). A key aspect in these endeavors is the detailed characterization of the $\mathrm{H}_{2}$ production under different conditions, for example at different oxygen levels. Two prominent methods for this are the electrochemical characterization of hydrogenases (Armstrong, this issue) and the online recording of $\mathrm{H}_{2}$ production/ consumption rates and of the rates of $H / D$ exchange between $\mathrm{D}_{2}$ and $\mathrm{H}_{2} \mathrm{O}$ by MIMS (Hemschemeier, Melis and Happe, this issue; Vignais 2005). The experimental set-up for the MIMS reactions is very similar to that described above, only that conditions are applied (e.g. larger sample volume, smaller inlet, thicker membrane) that reduce the gas consumption rates of the mass spectrometer (for details see Vignais 2005).

\section{Synthetic model systems}

With the dramatic anthropogenic increase in atmospheric $\mathrm{CO}_{2}$ concentration considerable interest has been created in 
the development of artificial water-splitting and hydrogenforming catalysts. These can be either molecular devices that are directly driven by light, or compounds covering an electrode surface that is eventually powered by electricity created in solar panels. If the catalysts are made of earthabundant materials, such an approach can provide the means for producing hydrogen from water in a sustainable way (Lubitz et al. 2008).

Membrane inlet mass spectrometry provides an ideal tool for studying, with high precision, the $\mathrm{O}_{2^{-}}$and $\mathrm{H}_{2^{-}}$ evolving activities of newly developed complexes, and in combination with isotope labeling unique information on the mechanisms and especially on the origin of the oxygen atoms of the generated $\mathrm{O}_{2}$ can be obtained. The latter becomes especially important if, in absence of a coupling of the compound to a light-driven oxidant/electrode, the reactivity of potential catalysts is probed with powerful chemical oxidants such as oxone, which often do themselves contain oxygen atoms that can be transferred to the catalytic sites. Figure 8 shows a rare result, where a dimeric Mn-complex produces upon the first oxone addition molecular oxygen with an isotope distribution closely resembling the expected values (squares on the left of Fig. 8) for true water-splitting (Beckmann et al. 2008). Simultaneously, often also strong $\mathrm{CO}_{2}$ evolution can be observed due to the (self)-oxidation of the organic framework of the compounds under investigation. For future studies, the coupling of MIMS with electrochemical devices becomes an interesting extension of this approach.

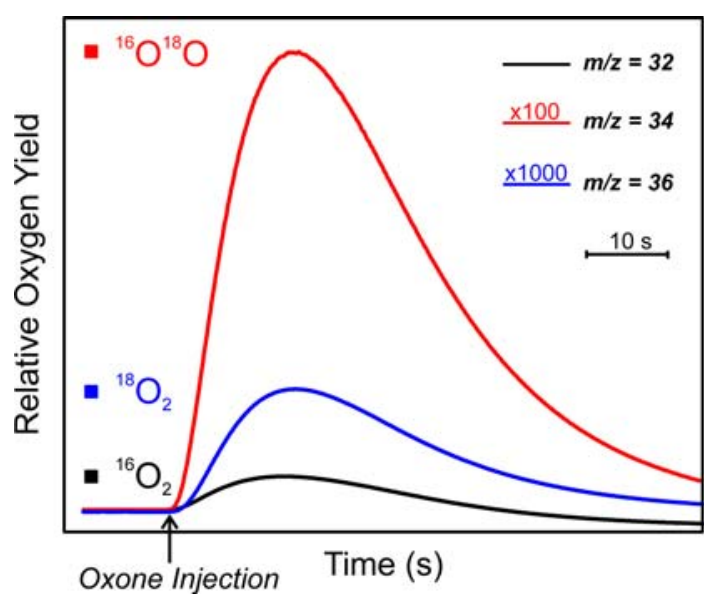

Fig. 8 Analysis of the water splitting activity of $\mathrm{Mn}_{2}$-bpmp-AcO after the injection of the oxidant oxone. The isotopic distribution of produced ${ }^{16} \mathrm{O}_{2}$ (black trace), ${ }^{16} \mathrm{O}^{18} \mathrm{O}$ (red trace) and ${ }^{18} \mathrm{O}_{2}$ (blue trace) is close to that expected for water oxidation to $\mathrm{O}_{2}$ at the employed $\mathrm{H}_{2}^{18} \mathrm{O}$ enrichment (squares) and thereby excludes the oxygen atoms of the unlabeled oxone as the source of oxygen under the employed experimental conditions. For more details see Beckmann et al. (2008)

\section{Concluding comments}

We hope that we were able to demonstrate in this short overview article that since its development in the early 1960s Membrane Inlet Mass Spectrometry has become an important technique for the study of gases, particularly those associated with photosynthetic reactions. But it is also seen as increasingly useful for testing catalytic enzymatic activity and catalysts for artificial water-splitting and hydrogen generation. The technique through the years has essentially remained unchanged in terms of the basic sampling design. However, the mass spectrometers have advanced tremendously both in terms of sensitivity and stability and additionally are increasingly equipped with multiple-ion collector arrays for detection of multiple ion signals. Such developments have opened up some tremendous new insights and MIMS has significant advances in terms of kinetic analysis and sample throughput. While we have concentrated here on examples closely related to photosynthesis, it is worth noting that this technique has had also a significant impact on many other fields, and has found essential applications in many different areas of research that involve gas evolution or consumption (for a recent review see Konermann et al. 2008).

Acknowledgments Support for this work was provided by the Australian Research Council DP0770149 (to WH \& TW) and the ARC center of excellence in Plant Energy Biology (to MRB), the Max-Planck Gesellschaft and the Wallenberg-Foundation (to JM).

\section{References}

Aoyama C, Suzuki H, Sugiura M, Noguchi T (2008) Flash-induced FTIR difference spectroscopy shows no evidence for the structural coupling of bicarbonate to the oxygen-evolving $\mathrm{Mn}$ cluster in photosystem II. Biochemistry 47:2760-2765

Armstrong AF, Badger MR, Day DA, Barthet MM, Smith PMC, Millar AH, Whelan J, Atkin OK (2008) Dynamic changes in the mitochondrial electron transport chain underpinning cold acclimation of leaf respiration. Plant Cell Environ 31:1156-1169

Audi G (2006) The history of nuclidic masses and of their evaluation. Int J Mass Spectrom 251:85-94

Bader KP, Renger G, Schmid GH (1993) A mass-spectrometric analysis of the water-splitting reaction. Photosynth Res 38:355361

Badger MR, Andrews TJ (1982) Photosynthesis and inorganic carbon usage by the marine Cyanobacterium, Synechococcus Sp. Plant Physiol 70:517-523

Badger MR, Price GD (1989) Carbonic anhydrase activity associated with the Cyanobacterium Synechococcus PCC7942. Plant Physiol 89:51-60

Badger MR, Palmqvist K, Yu JW (1994) Measurement of $\mathrm{CO}_{2}$ and $\mathrm{HCO}_{3}{ }^{-}$fluxes in Cyanobacteria and microalgae during steady state photosynthesis. Physiol Plant 90:529-536

Beckmann K, Uchtenhagen H, Berggren G, Anderlund MF, Thapper A, Messinger J, Styring S, Kurz P (2008) Formation of stoichiometrically ${ }^{18} \mathrm{O}$-labelled oxygen from the oxidation of ${ }^{18} \mathrm{O}$-enriched water mediated by a dinuclear manganese 
complex - a mass spectrometry and EPR study. Energy Environ Sci 1:668-676

Canvin DT, Berry JA, Badger MR, Fock H, Osmond CB (1980) Oxygen-exchange in leaves in the light. Plant Physiol 66:302307

Clausen J, Beckmann K, Junge W, Messinger J (2005) Evidence that bicarbonate is not the substrate in photosynthetic oxygen evolution. Plant Physiol 139:1444-1450

Coplen TB, Bohlke JK, De Bievre P, Ding T, Holden NE, Hopple JA, Krouse HR, Lamberty A, Peiser HS, Revesz K, Rieder SE, Rosman KJR, Roth E, Taylor PDP, Vocke RD, Xiao YK (2002) Isotope-abundance variations of selected elements-(IUPAC Technical Report). Pure Appl Chem 74:1987-2017

Espie GS, Miller AG, Birch DG, Canvin DT (1988) Simultaneous transport of $\mathrm{CO}_{2}$ and $\mathrm{HCO}_{3}{ }^{-}$by the Cyanobacterium Synechococcus Utex-625. Plant Physiol 87:551-554

Farquhar GD, Ehleringer JR, Hubick KT (1989) Carbon isotope discrimination and photosynthesis. Annu Rev Plant Phys 40:503-537

Gerster R (1971) Kinetics of oxygen exchange between gaseous $\mathrm{C}^{18} \mathrm{O}_{2}$ and water. Int $\mathrm{J}$ Appl Radiat Isot 22:339-348

Ghirardi ML, Dubini A, Yu J, Maness P-C (2009) Photobiological hydrogen-producing systems. Chem Soc Rev 38:52-61

Gibbons BH, Edsall JT (1963) Rate of hydration of carbon dioxide and dehydration of carbonic acid at 25 degrees. J Biol Chem 238:3502-3507

Govindjee, Weger HG, Turpin DH, van Rensen JJS, Devos OJ, Snel JFH (1991) Formate releases carbon dioxide/bicarbonate from thylakoid membranes-measurements by mass spectroscopy and infrared gas analyzer. Naturwissenschaften 78:168-170

Govindjee, Xu C, van Rensen JJS (1997) On the requirement of bound bicarbonate for photosystem II activity. Z Naturforsch 52:24-32

Guy RD, Fogel ML, Berry JA (1993) Photosynthetic fractionation of the stable isotopes of oxygen and carbon. Plant Physiol 101: 37-47

Hanson DT, Franklin LA, Samuelsson G, Badger MR (2003) The Chlamydomonas reinhardtii cia3 mutant lacking a thylakoid lumen-localized carbonic anhydrase is limited by $\mathrm{CO}_{2}$ supply to rubisco and not photosystem II function in vivo. Plant Physiol 132:2267-2275

Hendry G, Wydrzynski T (2003) ${ }^{18} \mathrm{O}$ isotope exchange measurements reveal that calcium is involved in the binding of one substrate water molecule to the oxygen-evolving complex in photosystem II. Biochemistry 42:6209-6217

Hillier W, Wydrzynski T (2000) The affinities for the two substrate water binding sites in the $\mathrm{O}_{2}$ evolving complex of photosystem II vary independently during S-state turnover. Biochemistry 39:4399-4405

Hillier W, Wydrzynski T (2004) Substrate water interactions within the Photosystem II oxygen evolving complex. Phys Chem Chem Phys 6:4882-4889

Hillier W, Messinger J, Wydrzynski T (1998) Kinetic determination of the fast exchanging substrate water molecule in the $\mathrm{S}_{3}$ state of photosystem II. Biochemistry 37:16908-16914

Hillier W, McConnell I, Badger MR, Boussac A, Klimov VV, Dismukes GC, Wydrzynski T (2006) Quantitative assessment of intrinsic carbonic anhydrase activity and the capacity for bicarbonate oxidation in photosystem II. Biochemistry 45:2094-2102

Hoch G, Kok B (1963) A mass spectrometer inlet system for sampling gases dissolved in liquid phases. Arch Biochem Biophys 101:160-170

Johnson RC, Cooks RG, Allen TM, Cisper ME, Hemberger PH (2000) Membrane introduction mass spectrometry: trends and applications. Mass Spectrom Rev 19:1-37
Kaltashov IA, Eyles SJ (2005) Mass spectrometry in biophysics. Conformation and dynamics of biomolecules. Wiley, Inc, Hoboken

Konermann 1, Messinger J, Hillier W (2008) Mass spectrometrybased methods for studying kinetics and dynamics in biological systems. In: Matysik J, Aartsma TJ (eds) Biophysical techniques in photosynthesis research, vol 2. Springer, The Netherlands, pp 167-190

Lindskog S, Coleman JE (1973) Catalytic mechanism of carbonic anhydrase. Proc Natl Acad Sci USA 70:2505-2508

Lubitz W, Reijerse EJ, Messinger J (2008) Solar water-splitting into $\mathrm{H}_{2}$ and $\mathrm{O}_{2}$ : design principles of photosystem II and hydrogenases. Energy Environ Sci 1:15-31

Maxwell K, Badger MR, Osmond CB (1998) A comparison of $\mathrm{CO}_{2}$ and $\mathrm{O}_{2}$ exchange patterns and the relationship with chlorophyll fluorescence during photosynthesis in C3 and CAM plants. Aust J Plant Physiol 25:45-52

McConnell IL, Badger MR, Wydrzynski T, Hillier W (2007) A quantitative assessment of the carbonic anhydrase activity in photosystem II. Bba-Bioenergetics 1767:639-647

McNevin DB, Badger MR, Kane HJ, Farquhar GD (2006) Measurement of (carbon) kinetic isotope effect by Rayleigh fractionation using membrane inlet mass spectrometry for $\mathrm{CO}_{2}$ consuming reactions. Funct Plant Biol 33:1115-1128

McNevin DB, Badger MR, Whitney SM, von Caemmerer S, Tcherkez GGB, Farquhar GD (2007) Differences in carbon isotope discrimination of three variants of D-ribulose-1,5-bisphosphate carboxylase/oxygenase reflect differences in their catalytic mechanisms. J Biol Chem 282:36068-36076

Melis A, Happe T (2004) Trails of green alga hydrogen researchfrom Hans Gaffron to new frontiers. Photosynth Res 80:401-409

Messinger J, Badger M, Wydrzynski T (1995) Detection of one slowly exchanging substrate water molecule in the S3 state of Photosystem II. Proc Natl Acad Sci USA 92:3209-3213

Mills GA, Urey HC (1940) The kinetics of isotopic exchange between carbon dioxide, bicarbonate ion, carbonate ion and water. J Am Chem Soc 62:1019-1026

Palmqvist K, Yu JW, Badger MR (1994) Carbonic-anhydrase activity and inorganic carbon fluxes in low $\mathrm{Ci}$ and high $\mathrm{Ci}$ cells of Chlamydomonas reinhardtii and Scenedesmus obliquus. Physiol Plant 90:537-547

Radmer RJ, Kok B (1976) Photoreduction of $\mathrm{O}_{2}$ primes and replaces $\mathrm{CO}_{2}$ assimilation. Plant Physiol 58:336-340

Radmer R, Ollinger O (1980a) Isotopic composition of photosynthetic $\mathrm{O}_{2}$ flash yields in the presence of $\mathrm{H}_{2}^{18} \mathrm{O}$ and $\mathrm{HC}^{18} \mathrm{O}_{3}{ }^{-}$. FEBS Lett 110:57-61

Radmer R, Ollinger O (1980b) Light-driven uptake of oxygen, carbon-dioxide, and bicarbonate by the green-alga Scenedesmus. Plant Physiol 65:723-729

Radmer R, Ollinger O (1986) Do the higher oxidation states of the photosynthetic $\mathrm{O}_{2}$-evolving system contain bound water? FEBS Lett 195:285-289

Radmer R, Kok B, Ollinger O (1978) Kinetics and apparent $K_{M}$ of oxygen cycle under conditions of limiting carbon dioxide fixation. Plant Physiol 61:915-917

Ribas-Carbo M, Robinson SA, Giles L (2005) The application of oxygen isotope technique to respiratory pathway partitioning. In: Lambers H, Ribas-Carbo M (eds) Plant respiration: from cell to ecosystem. Springer, Dordrecht, The Netherlands

Rost B, Richter KU, Riebesell U, Hansen PJ (2006) Inorganic carbon acquisition in red tide dinoflagellates. Plant Cell Environ 29:810-822

Ruuska SA, Badger MR, Andrews TJ, von Caemmerer S (2000) Photosynthetic electron sinks in transgenic tobacco with reduced amounts of Rubisco: little evidence for significant Mehler reaction. J Exp Bot 51:357-368 
Shevela D, Su JH, Klimov V, Messinger J (2008) Hydrogencarbonate is not a tightly bound constituent of the water-oxidizing complex in photosystem II. Bba-Bioenergetics 1777:532-539

Silva ACB, Augusti R, Dalmazio I, Windmoller D, Lago RM (1999) MIMS evaluation of pervaporation processes. Phys Chem Chem Phys 1:2501-2504

Silverman DN (1982) Carbonic anhydrase: oxygen-18 exchange catalyzed by an enzyme with rate-contributing proton-transfer steps. Methods Enzymol 87:732-752

Silverman DN, Lindskog S (1988) The catalytic mechanism of carbonic anhydrase: implications of a rate-limiting protolysis of water. Acc Chem Res s21:30-36

Singh S, Debus RJ, Wydrzynski T, Hillier W (2008) Investigation of substrate water interactions at the high-affinity $\mathrm{Mn}$ site in the photosystem II oxygen-evolving complex. Philos Trans Royal Soc B-Biol Sci 363:1229-1234

Siuzdak G, Bothner B, Yeager M, Brugidou C, Fauquet CM, Hoey K, Chang CM (1996) Mass spectrometry and viral analysis. Chem Biol 3:45-48

Tian GC, Klinman JP (1993) Discrimination between ${ }^{16} \mathrm{O}$ and ${ }^{18} \mathrm{O}$ in oxygen binding to the reversible oxygen carriers hemoglobin, myoglobin, hemerythrin, and hemocyanin: a new probe for oxygen binding and reductive activation by proteins. J Am Chem Soc 115:8891-8897

Tu CK, Silverman DN (1975) Kinetics of exchange of oxygen between carbon-dioxide and carbonate in aqueous-solution. J Phys Chem 79:1647-1651

Ulas G, Olack G, Brudvig GW (2008) Evidence against bicarbonate bound in the $\mathrm{O}_{2}$ evolving complex of photosystem II. Biochemistry 47:3073-3075

Vignais PM (2005) H/D exchange reactions and mechanistic aspects of the hydrogenase. Coord Chem Rev 249:1677-1690

Von Caemmerer S, Quinn V, Hancock NC, Price GD, Furbank RT, Ludwig M (2004) Carbonic anhydrase and C4 photosynthesis: a transgenic analysis. Plant Cell Environ 27:697-703

Woodger FJ, Badger MR, Price GD (2005) Sensing of inorganic carbon limitation in Synechococcus PCC7942 is correlated with the size of the internal inorganic carbon pool and involves oxygen. Plant Physiol 139:1959-1969 